\title{
THE NEW THREE-DIMENSIONAL VISUALIZATION METHOD OF HERITAGE SITES BY LIDAR DATA
}

\author{
Noritsuna FUJI ${ }^{*} \cdot$ Kiyohide SAITO ${ }^{* *} \cdot$ Tatsuro CHIBA $^{* * *} \cdot$ Ittetsu SATA $^{* * * *}$. \\ Tsuyoshi YOSHINAGA $^{* * * * *} \cdot$ Kouichiro TASAKI ${ }^{* * * * * *}$ \\ *Asia Air Survey Co.,Ltd. (Email:nor.fujii@ajiko.co.jp) \\ ${ }^{* *}$ Archaeological Institute of Kashihara, Nara Prefecture（Email: kiyohide@kashikoken.jp） \\ ${ }^{* * * *}$ Asia Air Survey Co.,Ltd. (Email: ta.chiba@ajiko.co.jp) \\ ${ }^{* * * * *}$ Asia Air Survey Co.,Ltd. (Email: itt.sata@ajiko.co.jp) \\ ${ }^{* * * * *}$ Asia Air Survey Co.,Ltd. (Email:tks.yoshinaga@ajiko.co.jp) \\ Asia Air Survey Co.,Ltd. (Email: ktr.tasaki@ajiko.co.jp)
}

Commission V, WG V/2

KEY WORDS: LiDAR, LaserScanner ,3D-Viewer, Heritage, Mounded tomb , Red Relief Image Map,Animation,

\begin{abstract}
:
We introduce a new visualization method for the three dimensional data with laser scanning from helicopter to express of the detailed landscape with "Red Relief Image Map (RRIM)"and “3D-Viewer". This RRIM and 3D-Viewer's method effectively represent 3D topographic information without any additional devices and stereopsis ability for the audience only through two dimensional medium and shows an appropriate form of every feature in the site. Chapters present what the laser scanning from helicopter is and show some examples of mounded tombs with RRIM and 3D-Viewer.

This visualization technique including detailed topographical information and geographical coordinates can be directly linked to CAD and GIS system, therefore the LiDAR can easily produce a contour line, a cross section and a bird's-eye view at any place as well as measure the height of trees.

This is different from other 3D topographic image with a shadow effect. Vegetation on the site is no longer obstacle to get detailed topographical information. Therefore, in Japan, this method is useful for huge mounded tombs thickly covered with trees, especially "Ryo-bo (imperial tomb)" which are administrated by the Imperial Household Agency and common people can't enter. Also a cluster of small mounded tombs which extend in the vast area called "Gunshufun" is shown effectively for the location of each mounded tomb. This method is suitable for understanding the structure of the sites in any wide spread archaeological fields. Moreover, in the management of heritages it is important that these data present precise information of the surface of lands to understand the present situation of heritages. Detailed topographical information by "LiDAR and Red Relief Image Map and 3DViewer" will open a new gate for managing of cultural heritage sites in the future.
\end{abstract}

\section{INTRODUCTION}

Although most survey maps of the gigantic mounded tomb in Japan were created 70 years or more ago, the geographical feature information which was acquired from a survey map is very important, in view of archaeology. However, the detailed survey of such gigantic mounded tomb is not easy.

In a ground survey, it is difficult to survey, these places since there is restriction of access and thick vegetation. Then, the LiDAR survey was applied in order to acquire the exact geographical feature information.Lidar survey for a large-sized ancient tomb was not performed in the past, but joint research with Kashihara Institute of Archeology carried out Lidar survey by helicopter for the first time. As a result, the detailed geographical feature information on a very precious large-sized ancient tomb and many small ancient tombs was able to be acquired.

The result of a survey is processed into the three-dimensional model by "Red Relief Image Map (RRIM)", and real image contents were created by $3 \mathrm{D}$ animation.

\section{LIDAR SURVEY}

LiDAR Survey uses the laser scanner system installed in the helicopter, it is the technology which measures earth surface with high density and highly exact,. (Fig. 1).

The laser light discharged from the laser scanner system arrives at the foundation from the crevice between the leaves of trees, and can measure detailed geographical feature.

Therefore, survey work can be done safely and quickly, without entering into a difficult ancient tomb.

In the case of a helicopter, it flies at an airraid altitude lower than a fixed wing, and can irradiate with more laser lights.

Therefore, it is possible to perform high-density measurement. It is high-density, and by being measurable, much laser light reaches the foundation side in a forest, and it can measure the form of more detailed geographical feature.The used helicopter (Robinson R44) is shown in Fig. 2. The used Laser scanner system (Harrier56 by TopoSys) is shown in Fig. 3. 
International Archives of the Photogrammetry, Remote Sensing and Spatial Information Sciences, Volume XXXIX-B5, 2012 XXII ISPRS Congress, 25 August - 01 September 2012, Melbourne, Australia

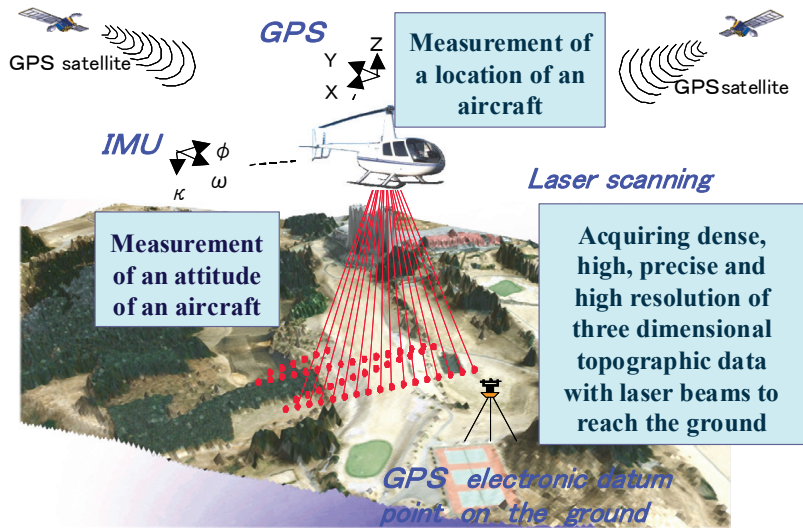

Fig 1. LiDAR Survey concept

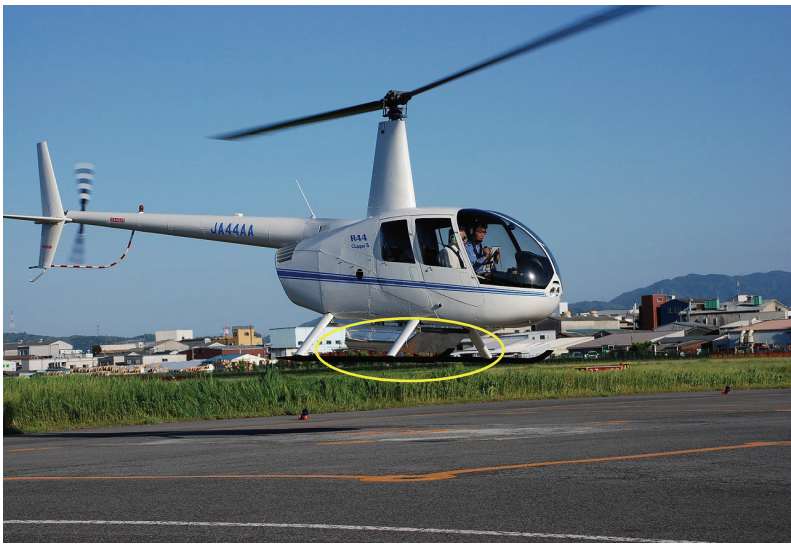

Fig 2. Hellicopter(R44) and Laser scanner system

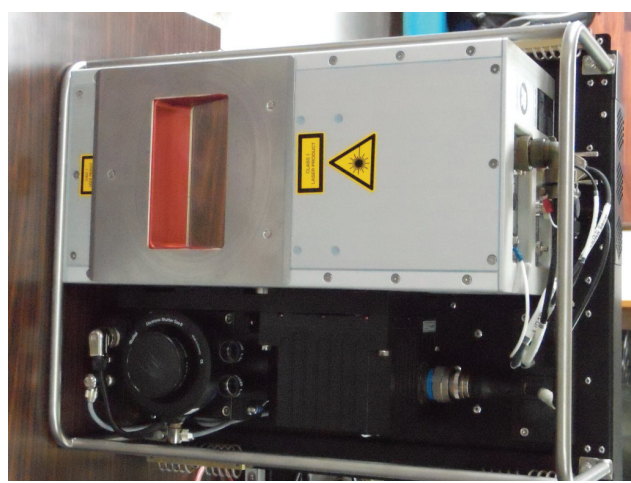

Fig 3. Laser scanner system (Harrier56 by TopoSys)

The Konabe ancient tomb was investigated on December 7 , 2009. and the Gobyouyama ancient tomb was investigated on February 21, 2010. It carried out in the measurement specifications of Table 1 . In both of ancient tombs, trees had grown thick, and the ground in an ancient tomb could not be seen almost from the outside of the canal.

The flight plan set up four course lines of crossing. and raised the transport factor to the laser light by changing the degree of angle of approach of the laser light.

By having performed high-density measurement by Lidar survey, the data of the surface of trees, the middle class, and a ground side have been acquired.

The part which becomes the shade of trees and cannot be measured was also able to perform data acquisition of ground height by measurement from four directions.
Furthermore, We were able to understand the growth situation with trees by the sectional view. (Fig. 6, Fig. 7)

Table 1. Specification of Lidar survey

\begin{tabular}{|c|c|c|c|}
\hline & Gobyouyama & Konabe & Nizawa-senduka \\
\hline Flight line & 4 & 4 & 7 \\
\hline $\begin{array}{c}\text { Flight } \\
\text { fhght(AGL) }\end{array}$ & $500 \mathrm{~m}$ & $650 \mathrm{~m}$ & $500 \mathrm{~m}$ \\
\hline Pulse rate & $180 \mathrm{kHz}$ & $120 \mathrm{kHz}$ & $180 \mathrm{kHz}$ \\
\hline Scan angle & $\pm 30 \mathrm{deg}$ & $\pm 30 \mathrm{deg}$ & $\pm 30 \mathrm{deg}$ \\
\hline $\begin{array}{c}\text { Flight } \\
\text { Speed }\end{array}$ & $70 \mathrm{~km} / \mathrm{h}$ & $70 \mathrm{~km} / \mathrm{h}$ & $70 \mathrm{~km} / \mathrm{h}$ \\
\hline Density & $30 \mathrm{points} / \mathrm{m}^{2}$ & $\begin{array}{c}10 \mathrm{points} / \\
\mathrm{m}^{2}\end{array}$ & $30 \mathrm{points} / \mathrm{m}^{2}$ \\
\hline
\end{tabular}

\section{RED RERIEF IMAGE MAP}

On Red Relief Image Map, as slopes became steeper, they become redder, and ridges are whiter compared to the darker black valleys. Red Relief Image Map is a pseudo color image. It is result of synthesizing mathermathically converted images through various topographic filtering. This is a complementely unique technique of relief visualization that is significantly different from conventional shaded relief maps and bird's eye view maps. RRIM is Visualization processing system,

Visualization Processing Method, and Visualization Processing Program. (Japan Patent No 3670274,C.N..Patent Application No.200380102752.9,U.S.Patent Application No.10/553,675)

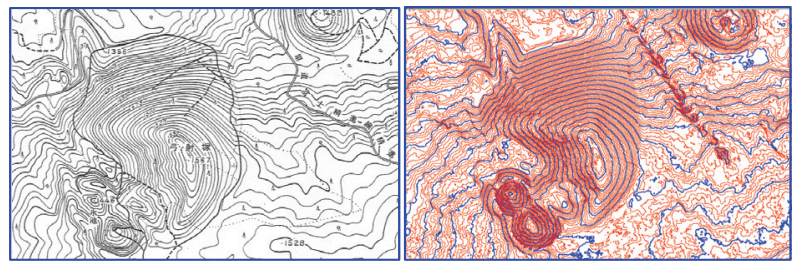

General contour map Contour map by airborne laser scanning

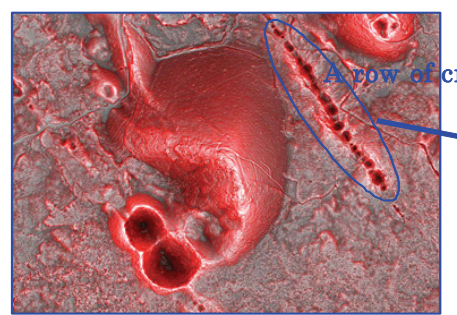

Red relief image map

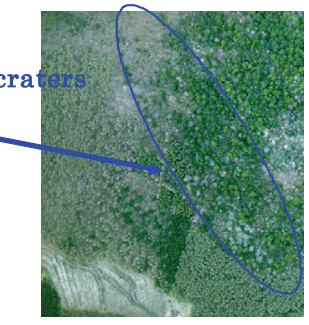

Aerial photo
Fig 4. Red Relief Image Map (Aokigahara:West of Mt.Fuji)

\section{KONABE MOUNDED TOMB}

Konabe mounded tomb is located at Hokkeji-cho, Nara city, Nara prefecture and is taken charge of the Imperial Household Agency as a tomb of one of candidates of a member of the Imperial family. This mounded tomb is a keyhole shape which a square part of the tomb faces to the south. Konabe mounded tomb was constructed around the early five century A.D. The mound consists of three-tier and is constricted in the middle which projecting parts are fitted in the east and west side. This tomb constitutes a part of Saki-Tatenami mounded tomb group. A moat surrounds the mounded tomb and subordinate small tombs in line exist on the bank of the moat. The mound is $204 \mathrm{~m}$ length and the circle part is $125 \mathrm{~m}$ diameter and $20 \mathrm{~m}$ height. The square part is $129 \mathrm{~m}$ width and $17.5 \mathrm{~m}$ height. 
International Archives of the Photogrammetry, Remote Sensing and Spatial Information Sciences, Volume XXXIX-B5, 2012 XXII ISPRS Congress, 25 August - 01 September 2012, Melbourne, Australia

Airborne LiDAR scanning was carried out in December 2009 from the flying height of $650 \mathrm{~m}$ with a helicopter. This aircraft had a nominal ground speed of approximately $70 \mathrm{~km}$ per hour and the laser was operated at a pulse rate of $120 \mathrm{KHz}$. The aircraft flew over the mounded tomb with two pairs of parallel lines crisscrossing to form a stylized. 120 thousand shots per second were fired and more than 10 laser shots per square meter were collected as data of the ground level.

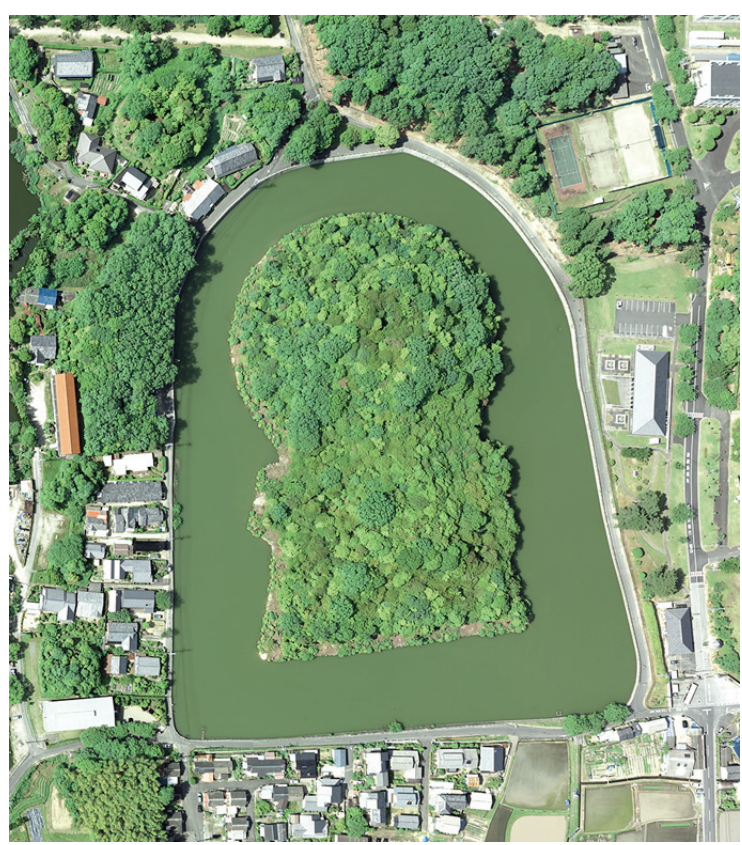

Fig 4. Konabe Mounded Tomb (Photo Image by DMC )

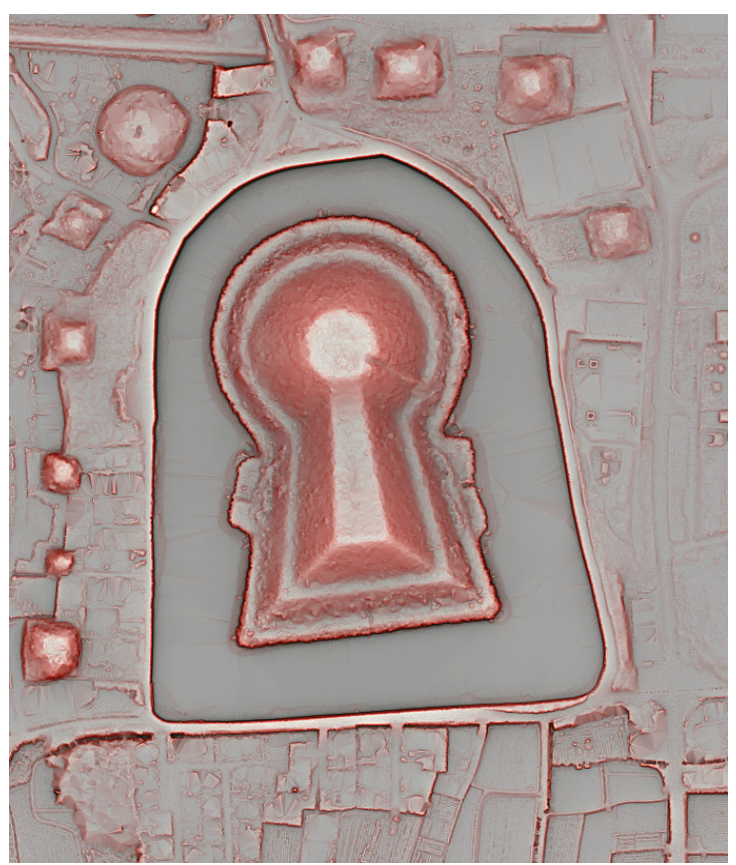

Fig 5. Konabe Mounded Tomb (RRIM of Lidar data)

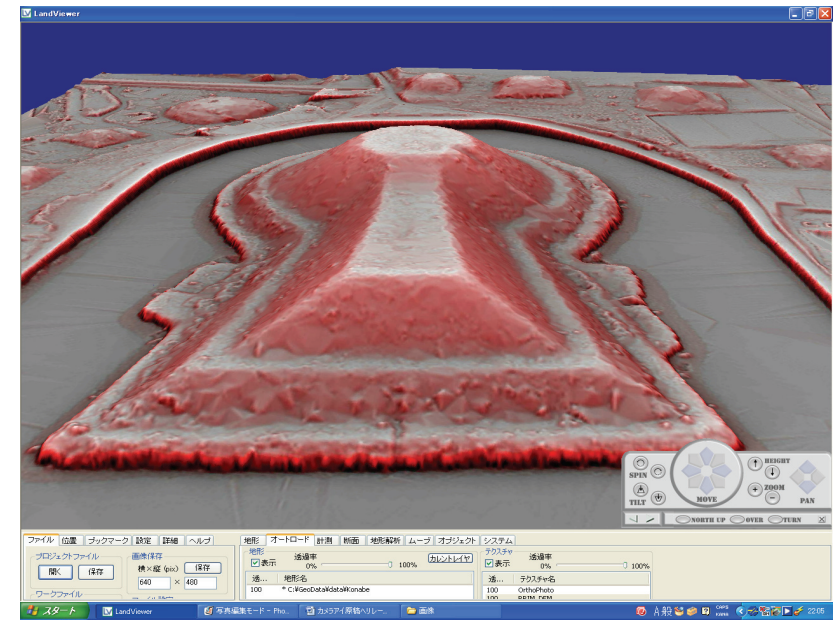

Fig 6. Konabe Mounded Tomb (Bird Eyes image by Viewer)

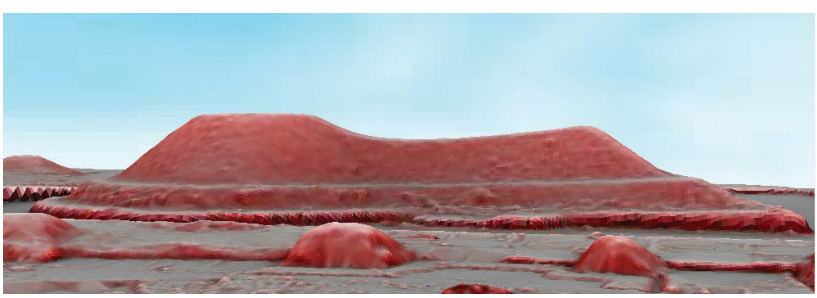

Fig 7. Konabe Mounded Tomb (Bird Eyes image on ground by Viewer)

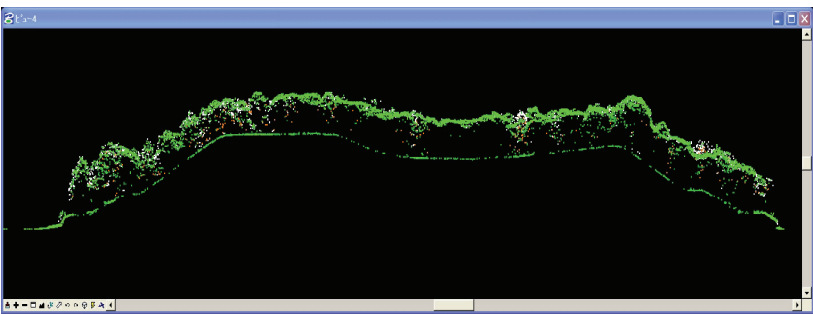

Fig8. Vegetatin structure in Konabe Mounded Tomb

\section{GOBYOYAMA MOUNDED TOMB}

Gobyoyama mounded tomb is located at Mozuhonmachi, Kitaku, Sakaishi, Osaka prefecture and is taken charge of the Imperial Household Agency as a tomb of one of candidates of a member of the Imperial family. This mounded tomb is a keyhole shape which a square part of the tomb faces to the west Gobyoyama mounded tomb constitutes a part of Mozu mounded tomb group and is the fourth in scale.

In 2008 the Imperial Household Agency and Sakai City excavated at the foot of this mounded tomb and a part of moat for moat shore protection work. Gobyoyama mounded tomb was constructed around the middle of the fifth century A.D. The mound consists of three-tier and is constricted in the middle which the projecting part is fitted in the south. A line of Haniwa cylinders was set up on every tier. Double moats surround the mounded tomb. The mound is $200 \mathrm{~m}$ length and the circle part is $110 \mathrm{~m}$ diameter and $20 \mathrm{~m}$ height. The square part is $120 \mathrm{~m}$ width and $18 \mathrm{~m}$ height. At the mounded tomb was thickly covered with trees same as Konabe mounded tomb.

Airborne LiDAR scanning was carried out in February 2010 from the flying height of $500 \mathrm{~m}$ with a helicopter. This aircraft had a nominal ground speed of approximately $70 \mathrm{~km}$ per hour and the laser was operated at a pulse rate of $180 \mathrm{KHz}$. The 
aircraft flew over the mounded tomb with two pairs of parallel lines crisscrossing to form a stylized. 180 thousand shots per second were fired and more than 30 laser shots per square meter were collected as data of the ground level.

In 2008 according to the ownership of land the Imperial Household Agency surveyed the mound area and Sakai City surveyed the area of the moat and outside the moat in the technique of analog. Therefore we could compare the contour map from 3D scanning and from the traditional survey by the Imperial Household Agency and Sakai City. With this comparison elevations of tops in the circle part and square part of the mounded tomb showed only a few centimeters difference. The shape of the plan didn't show any difference and contours were completely overlapped each other. However, there is a difference in contours on the second tier which expressed small strip mounds at right angles to contours of the mounded tomb in 3D scanning contour map. Small strip mounds actually existed. Those weren't any facilities of the mound. They were collection places for trees which were cut down. Moreover, there are contours extending to the moat like projections and isolating like islands. These contours indicate aquatic plants floating on the moat. It means that $3 \mathrm{D}$ scanning map showed precise information on and around the mound.

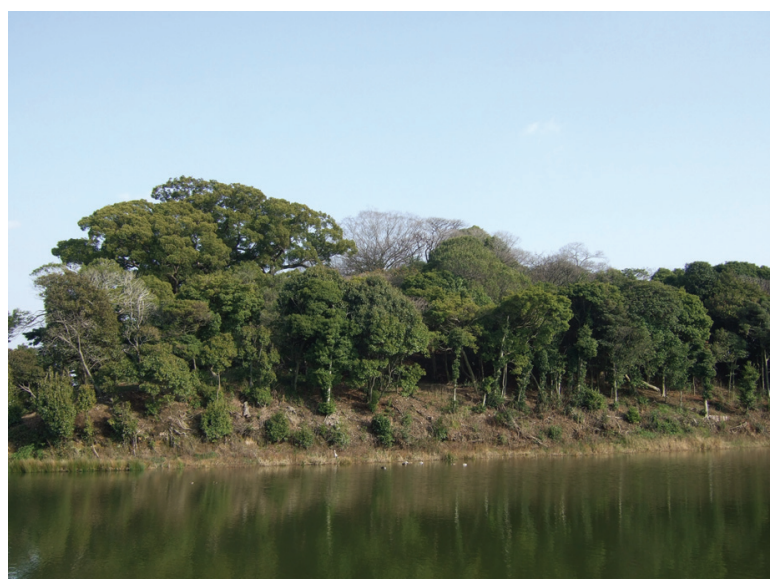

Photo1. Gobyouyama Mounded Tomb

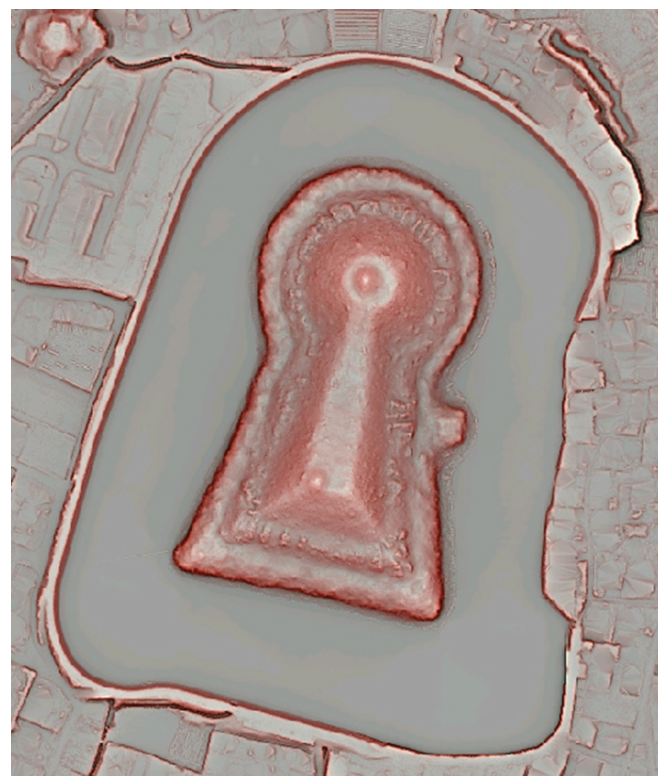

Fig9. Gobyouyama Mounded Tomb(RRIM of Lidar data)

\section{A CLUSTER OF SMALL MOUNDED TOMBS CALLED NIZAWA-SENDUKA}

With acquirement of magnificent result in gigantic mounded tombs with $3 \mathrm{D}$ scanning we were encouraged to carry out $3 \mathrm{D}$ scanning to the cluster of small mounded tombs. We chose Nizawa-senduka cluster of small mounded tombs which a survey map of mounds was drawn in previous research.

Nizawa-senduka cluster of small mounded tombs is located at small foot hills of Kitaochi-cho and Kawanichi-cho, Kashiara city in the south of Nara basin. About six hundreds mounded tombs consisting of small circle-shape mound tombs around 10 $-15 \mathrm{~m}$ diameter were constructed on the hills from the end of 4 A.D. to the first half of 6 A.D. In early 1960's about hundred mounded tombs were excavated to protect from a development to expand in the agricultural production by the Japanese government. Through excavations many new archaeological evidences such as a structure of the cluster of small mounded tombs, a process of formation to the cluster with constructing mounded tombs and the diversity of burial goods including continental taste became definite. Most of the area around $124,427 \mathrm{~m}^{2}$ of the cluster of mounded tomb called Nizawasennduka was designated as a national historic monument (Saito 1991). The half of the area of mounded tombs has been kept in good condition under trees.

Airborne LiDAR scanning was carried out in March 2011 from the flying height of $500 \mathrm{~m}$ with a helicopter. This aircraft had a nominal ground speed of approximately $70 \mathrm{~km}$ per hour and the laser was operated at a pulse rate of $180 \mathrm{KHz}$. The aircraft flew over the cluster of small mounded tombs with two pairs of parallel lines crisscrossing to form a stylized. 180 thousand shots per second were fired and more than 30 laser shots per square meter were collected as data of the ground level.

We had got the detailed and precious geographical feature data of many small ancient tombs by Lidar survey. and It presented precise information of location of small mounds on the hill and existence moats around some keyhole-shape mounded tombs.

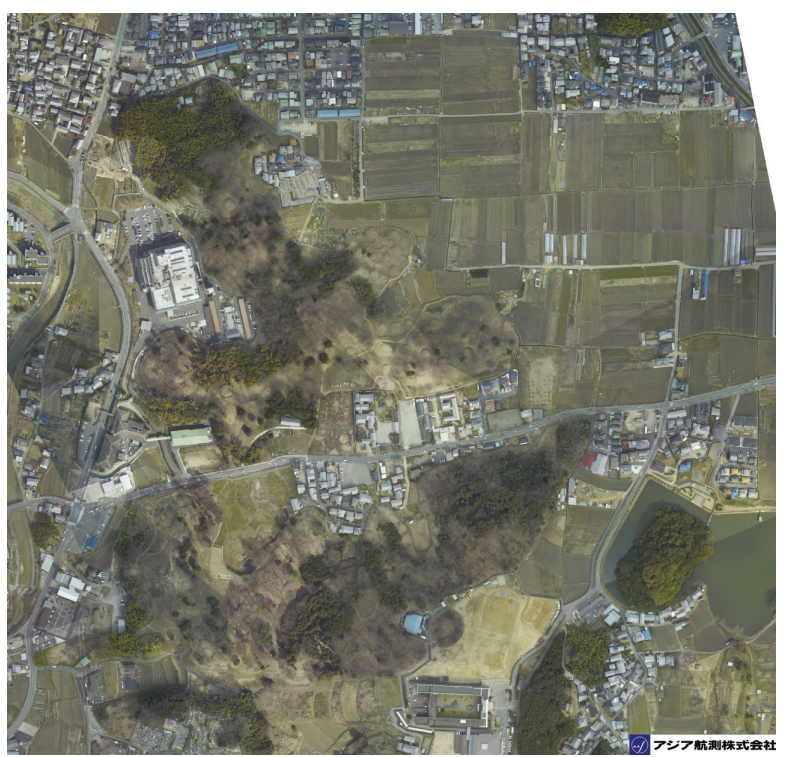

Fig10. Nizawa-senduka (Ortho Photo Image) 
International Archives of the Photogrammetry, Remote Sensing and Spatial Information Sciences, Volume XXXIX-B5, 2012 XXII ISPRS Congress, 25 August - 01 September 2012, Melbourne, Australia

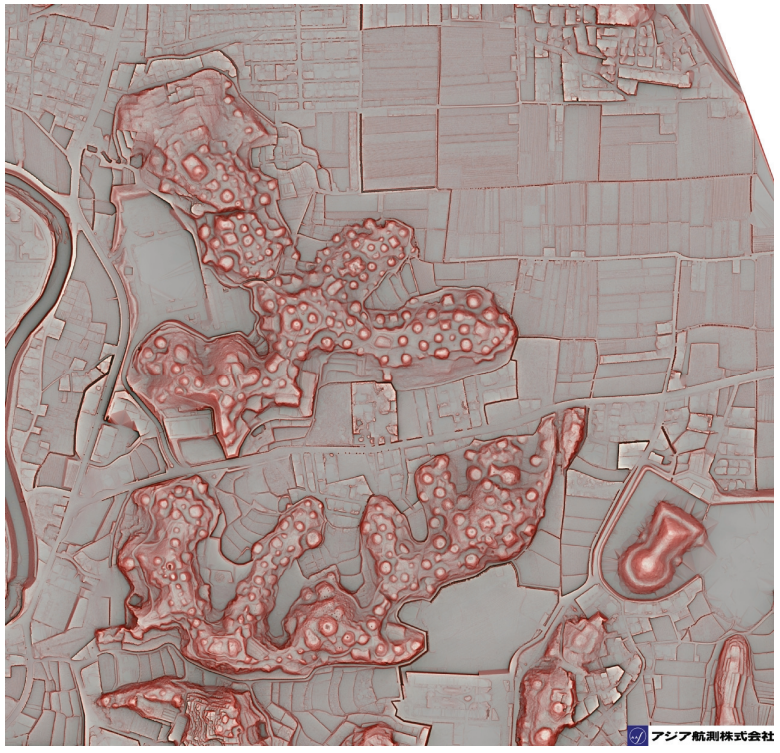

Fig11. Nizawa-senduka (RRIM of Lidar data)

(1)The discovery of a new keyhole-shape mounded tomb A large keyhole-shaped tomb mound, which had been unidentified until recntly, was discovered in the bamboo grove located in the south east of Niizawa Senzuka's tumulus group. Since the tomb's height is less than 3meters, it was not recognized as an ancient tomb. Although LASER light takes time to travel to the ground in the bamboo grove and scanning the landscape is difficult, the high-density measurement using helicopter laser surveying led to the discovery of the ancient tomb.

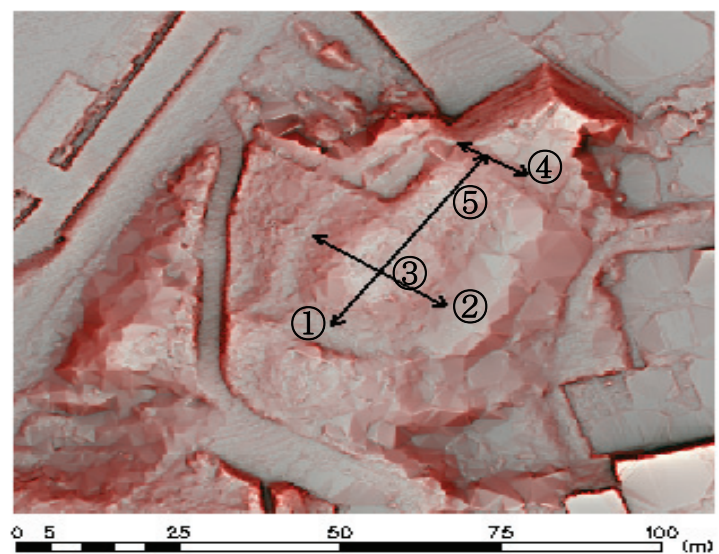

Fig12. A New keyhole-shape mounded tomb (RRIM of Lidar)

Table 2. Length of a new keyhole-shape mounded tomb

\begin{tabular}{|c|c|}
\hline (1)Full length & $41.72 \mathrm{~m}$ \\
\hline (2)Diameter in the circle part & $24.83 m$ \\
\hline (3)Height in the circle part & $\begin{array}{c}2.11 \mathrm{~m} \\
\text { (Altitude 89.75m) }\end{array}$ \\
\hline (4)Wide in the square part & $12.29 \mathrm{~m}$ \\
\hline (5)Height in the square part & $\begin{array}{c}2.74 \mathrm{~m} \\
\text { (Altitude } 88.57 \mathrm{~m})\end{array}$ \\
\hline
\end{tabular}

(2) Confirmation of a new tomb shape In the 17th tomb of Niizawa Senzuka's tumulus group, a tomb having a circular tomb mounted on top of a rectangular tomb (deformed keyhole-shaped tomb) was confirmed.

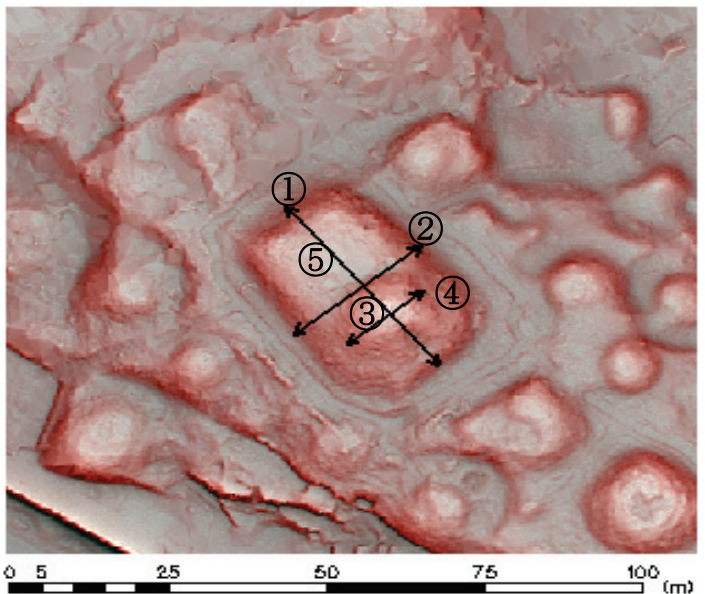

Fig13. A New tomb shape (RRIM of Lidar data)

Table 3. Length of a Confirmation of a new tomb shape

\begin{tabular}{|l|c|}
\hline (1)Full length & $\mathbf{3 8 . 2 5 m}$ \\
\hline (2)Wide length & $25.72 \mathrm{~m}$ \\
\hline (3)Height in the square part & $\begin{array}{c}\mathbf{2 . 4 6 m} \\
\text { (Altitude } 91.35 \mathrm{~m} \text { ) }\end{array}$ \\
\hline (4)Diameter in the circle part & $\mathbf{1 5 . 6 2 \mathrm { m }}$ \\
\hline (5)Height in the circle part & $\begin{array}{c}2.24 \mathrm{~m} \\
\text { (Altitude } 93.59 \mathrm{~m} \text { ) }\end{array}$ \\
\hline
\end{tabular}

\section{THREE-DIMENSIONAL DISPLAY OF RED RELIEF IMAGE MAP, AND CREATION OF 3D MOVIE}

Processing result of Lidar survey into a three-dimensional model, and using 3D viewer system "LandViewer" of our development as analyze of geographical feature, The threedimensional display picture and 3D movie of the red topographical map which can grasp discovery of a new keyhole-shaped mounted and new presentation of a gigantic mounded tombs and others form at a glance were created.

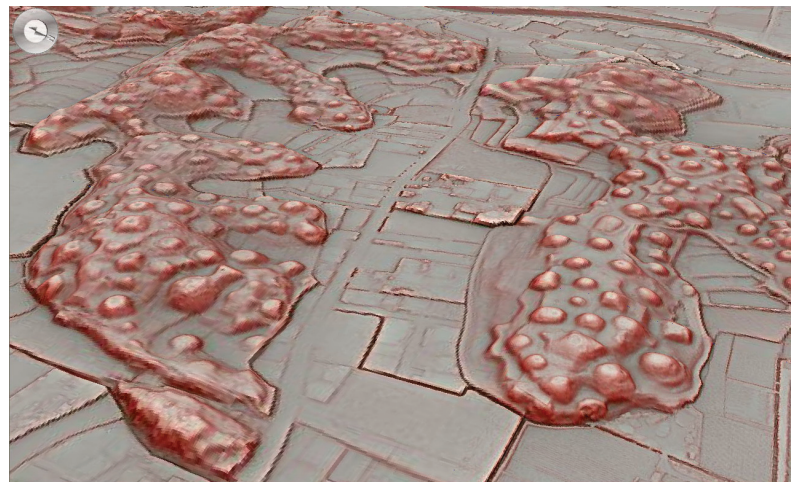

Fig14. Animation by Land-Viewer (RRIM of Lidar) 


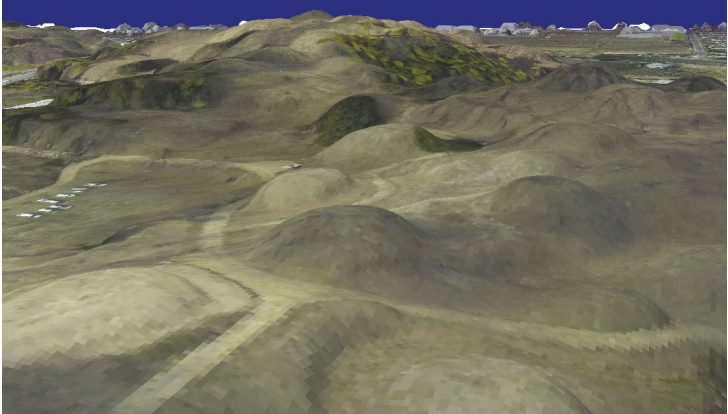

Fig15. Animation by Land-Viewer (OrthophotoImage+ Lidar)

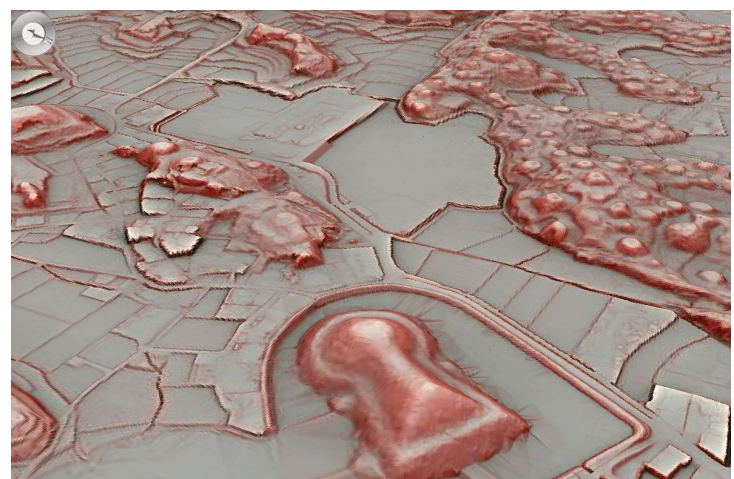

Fig16. Animation by Land-Viewer (RRIM of Lidar)

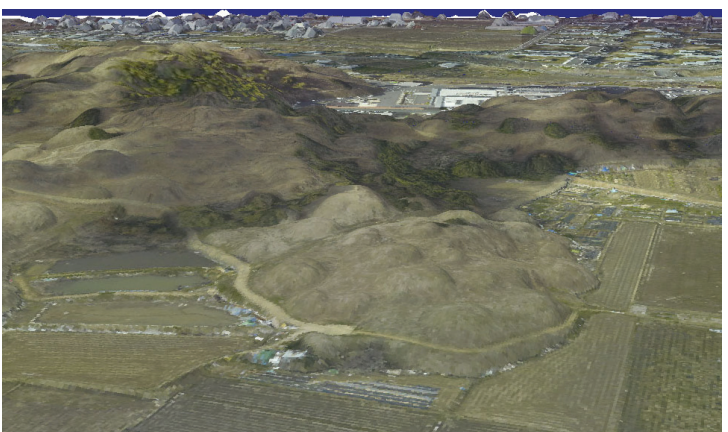

Fig17. Animation by Land-Viewer (OrthophotoImage+ Lidar)

\section{CONCLUSION}

By use of Helibone-Lidar survey, it was possible to obtain the micro topography of ancient tombs without stepping into the tomb region which is coverd with vegetation. The collection of geographical information from innumerable burial mounds of large ancient tombs, which are difficult for human's to access, is made possible by this measurement method. The result shows a great significance in future academics and social education.

This method and aviation laser measurement highlight the "formative beauty" of a large keyhole-shaped tomb mound by using the technology of red relief image map - our patented technology (Patent number 3670274). Further, topographical mapping accurately shows that the large keyhole-shaped tomb was constructed using in-depth knowledge of three-dimensional modeling.

Similar to the large ancient tombs, from Niizawa Senzuka's tumulus group, which is densely covered with small ancient tombs, detailed information was obtained, and the location of each ancient tomb were clearly visualized.

This method is also effective in measuring cultural heritage besides ancient tombs and can be applied to understand a wide range of monuments and remnants. Through this method, one can collect information regarding the location, distribution, and structure of monuments even in forest areas (e.g., tropical rainforests); in hazardous areas (landmines or natural disaster regions); and in remnants of land parcels (paddy fields, irrigation, etc.).

\section{REFERENCE}

[1]Chase, Arien, D. Chase, J. Weishampel, J. Drake, R. Shrestha, K. Slatton, J. Awe and W. Carter 2010 Airborne LiDAR, archaeology, and the ancient Maya landscape at Caracol, Belize, Journal of Archaeological Science, pp1-12.

[2]Chiba, Tatsuro, S. Kaneta and Y. Suzuki 2008 Red Relief Image Map: New Vi0sualization Method for Three Dimensional Data, The International Archives of the Photogrammetry, Remote Sensing and Spatial Information Sciences. Vol. XXXVII, pp.1071-1076.

[3]Fagan, Brain 2005 A Brief History of Archaeology: Classical Times to the Twenty-First Century, Pearson Education, Inc.

[4]Saito, Kiyohide 1991 Nizawa-senduka Kofungun(新沢千塚 古墳群), Diagram Historic remains of Japan Vol.3 (図説日 本の史跡 原始 3 ), 77-79, Douhou Press. (in Japanese).

[5]Suenaga, Masao 1961 Japanese Mounded Tombs, Asahi Newspaper Co. (in Japanese).

[6]Fujii,noritsuna, Saito, Kiyohide 2011 Journal of Japan Society of Photogrammetry and Remote Senisng, kamera-eye 2011.No.1 2-3 